\title{
Quantitative multimodal multiparametric imaging in Alzheimer's disease
}

\author{
Qian Zhao $\cdot$ Xueqi Chen $\cdot$ Yun Zhou
}

Received: 16 September 2015/ Accepted: 7 December 2015/Published online: 8 January 2016

(C) The Author(s) 2015. This article is published with open access at Springerlink.com

\begin{abstract}
Alzheimer's disease (AD) is a progressive neurodegenerative disorder, causing changes in memory, thinking, and other dysfunction of brain functions. More and more people are suffering from the disease. Early neuroimaging techniques of $\mathrm{AD}$ are needed to develop. This review provides a preliminary summary of the various neuroimaging techniques that have been explored for in vivo imaging of $\mathrm{AD}$. Recent advances in magnetic resonance (MR) techniques, such as functional MR imaging (fMRI) and diffusion MRI, give opportunities to display not only anatomy and atrophy of the medial temporal lobe, but also at microstructural alterations or perfusion disturbance within the AD lesions. Positron emission tomography (PET) imaging has become the subject of intense research for the diagnosis and facilitation of drug development of AD in both animal models and human trials due to its non-invasive and translational characteristic. Fluorodeoxyglucose (FDG) PET and amyloid PET are applied in clinics and research departments. Amyloid beta $(\mathrm{A} \beta)$ imaging using PET has been recognized as one of the most important methods for the early diagnosis of $\mathrm{AD}$, and numerous candidate compounds have been tested for $A \beta$ imaging. Besides in vivo imaging method, a lot of ex vivo
\end{abstract}

\section{Q. Zhao}

Department of Nuclear Medicine, General Hospital of Ningxia Medical University, Yinchuan 750004, China

X. Chen · Y. Zhou $(\bowtie)$

The Russell H. Morgan Department of Radiology and Radiological Science, Johns Hopkins University School of Medicine, Baltimore, MD 21287, USA

e-mail: yunzhou@jhmi.edu

X. Chen · Y. Zhou

Department of Nuclear Medicine, Peking University First Hospital, Beijing 100034, China modalities are being used in the AD researches. Multiphoton laser scanning microscopy, neuroimaging of metals, and several metal bioimaging methods are also mentioned here. More and more multimodality and multiparametric neuroimaging techniques should improve our understanding of brain function and open new insights into the pathophysiology of $\mathrm{AD}$. We expect exciting results will emerge from new neuroimaging applications that will provide scientific and medical benefits.

Keywords Alzheimer's disease - Neuroimaging - PET · MRI $\cdot$ Amyloid beta $\cdot$ Multimodal

\section{Introduction}

Alzheimer's disease (AD) is a progressive neurodegenerative disorder that gradually destroys brain cells, causing changes in memory, thinking, and other dysfunction of brain functions [1]. AD is considered to a prolonged preclinical stage where neuropathological changes precede the clinical symptoms [2]. An estimation of 35 million people worldwide is living with this disease. If effective treatments are not discovered in a timely fashion, the number of $\mathrm{AD}$ cases is anticipated to rise to 113 million by 2050 [3].

Amyloid beta $(A \beta)$ and tau are two of the major biomarkers of $\mathrm{AD}$, and have important and different roles in association with the progression of AD pathophysiology. Jack et al. established hypothetical models of the major biomarkers of $\mathrm{AD}$. By renewing and modifying the models, they found that the two major proteinopathies underlying AD biomarker changes, $A \beta$ and tau, may be initiated independently in late onset $\mathrm{AD}$ where they hypothesize that an incident $A \beta$ pathophysiology can accelerate an antecedent limbic and brainstem tauopathy [4]. MRI technique 
was used in the article, which revealed that the level of $A \beta$ load was associated with a shorter time-to-progression of $\mathrm{AD}$ [5]. This warrants an urgent need to develop early neuroimaging techniques of AD neuropathology that can detect and predict the disease before the onset of dementia, monitor therapeutic efficacy in halting and slowing down progression in the earlier stage of the disease.

There have been various reports on the imaging assessments of AD. Some measurements reflect the pathology of AD directly, including positron emission tomography (PET) amyloid imaging and cerebrospinal fluid (CSF) betaamyloid 42 (A $\beta 42)$, while others reflect neuronal injury associated with AD indirectly, including CSF tau (total and phosphorylated tau), fluorodeoxy-D-glucose (FDG)-PET, and MRI. AD Neuroimaging Initiative (ADNI) has been to establish the optimal panel of clinical assessments, MRI and PET imaging measures, as well as other biomarkers from blood and CSF, to inform clinical trial design for $\mathrm{AD}$ therapeutic development. At the same time, it has been highly productive in generating a wealth of data for elucidating disease mechanisms occurring during early stages of preclinical and prodromal AD [6].

Single neuroimaging often reflects limit information of AD. As a result, multimodal neuroimaging is widely used in neuroscience researches, as it overcomes the limitations of individual modalities. Multimodal multiparametric imaging mean the combination of different imaging techniques, such as PET, MRI, simultaneously or separately. The multimodal multiparametric imaging enables the visualization and quantitative analysis of the alterations in brain structure and function, such as PET/CT, and PET/ MRI. [7]. In this review article, we summarize and discuss the main applications, findings, perspectives as well as advantages and challenges of different neuroimaging in AD, especially MRI and PET imaging.

\section{Magnetic resonance imaging}

MRI demonstrates specific volume loss or cortical atrophy patterns with disease progression in AD patients [8-10]. There are several MRI techniques and analysis methods used in clinical and scientific research of AD. Recent advances in MR techniques, such as functional MRI (fMRI) and diffusion MRI, depict not only anatomy and atrophy of the medial temporal lobe (MTL), but also microstructural alterations or perfusion disturbance within this region.

\subsection{Functional MRI}

Because of the cognitive reserve (CR), the relationship between severity of AD patients' brain damage and corresponding clinical symptoms is not always paralleled [11, 12]. Recently, resting-state fMRI (RS-fMRI) is popular for its ability to map brain functional connectivity noninvasively [13]. By using RS-fMRI, Bozzali et al. reported that the $\mathrm{CR}$ played a role in modulating the effect of $\mathrm{AD}$ pathology on default mode network functional connectivity, which account for the variable clinical symptoms of AD [14]. Moreover, AD patients with higher educated experience were able to recruit compensatory neural mechanisms, which can be measured using RS-fMRI. Arterial spin-labeled (ASL) MRI is another functional brain imaging modality, which measures cerebral blood flow (CBF) by magnetically labeled arterial blood water following through the carotid and vertebral arteries as an endogenous contrast medium. Several studies have concluded the characteristics of $\mathrm{CBF}$ changes in $\mathrm{AD}$ patients using ASL-MRI [15-17].

At some point in time, sufficient brain damage accumulates to result in cognitive symptoms and impairment. Mild cognitive impairment (MCI) is a condition in which subjects are usually only mildly impaired in memory with relative preservation of other cognitive domains and functional activities and do not meet the criteria for dementia [18], or as the prodromal state AD [19]. MCI patients are at a higher risk of developing $\mathrm{AD}$ and up to $15 \%$ convert to AD per year [18]. Binnewijzend et al. have reported the pseudocontinuous ASL could distinguish both MCI and AD from healthy controls, and be used in the early diagnosis of AD [20]. In their continuous study, they used quantitative whole brain pseudocontinuous ASL to compare regional $\mathrm{CBF}(\mathrm{rCBF})$ distribution patterns in different types of dementia, and concluded that ASL-MRI could be a non-invasive and easily accessible alternative to FDG-PET imaging in the assessment of CBF of $\mathrm{AD}$ patients [21].

\subsection{Structure MRI}

Structural MRI (sMRI) has already been a reliable imaging method in the clinical diagnosis of $\mathrm{AD}$, characterized as gray matter reduction and ventricular enlargement in standard T1-weighted sequences [9]. Locus coeruleus (LC) and substantia nigra (SN) degeneration was seen in AD. By using new quantitative calculating method, Chen et al. presented a new quantitative neuromelanin MRI approach for simultaneous measurement of locus LC and SN of brainstem in living human subjects [22]. The approach they used demonstrated advantages in image acquisition, preprocessing, and quantitative analysis. Numerous transgenic animal models of amyloidosis are available, which can manipulate a lot of neuropathological features of $\mathrm{AD}$ progression from the deposition of $\beta$-amyloid [23]. Braakman et al. demonstrated the dynamics of amyloid plaque 
formation and development in a serial MRI study in a transgenic mouse model [24]. Increased iron accumulation in gray matter is frequently observed in AD. Because of the paramagnetic nature of iron, MRI shows nice potential in the investigating iron levels in AD [25]. Quantitative MRI was shown high sensitivity and specificity in mapping cerebral iron deposition, and helped in the research on AD diagnosis [26].

The imaging patterns are always associated with the pathologic changes, such as specific protein markers. Spencer et al. manifested the relationship between quantitative $\mathrm{T} 1$ and $\mathrm{T} 2$ relaxation time changes and three immunohistochemical markers: $\beta$-amyloid, neuron-specific nuclear protein (a marker of neuronal cell load), and myelin basic protein (a marker of myelin load) in $\mathrm{AD}$ transgenic mice [27].

High-field MRI has been successfully applied to imaging plaques in transgenic mice for over a decade without contrast agents [24, 28-30]. Sillerud et al. devised a method using blood-brain barrier penetrating, amyloidtargeted, superparamagnetic iron oxide nanoparticles (SPIONs) for better imaging of amyloid plaque [31]. Then, they successfully used this SPION-MRI to assess the drug efficacy on the $3 \mathrm{D}$ distribution of $\mathrm{A} \beta$ plaques in transgenic AD mouse [32].

\subsection{Diffusion MRI}

Diffusion-weighted imaging (DWI) is a sensitive tool that allows quantifying of physiologic alterations in water diffusion, which result from microscopic structural changes.

Diffusion tensor imaging (DTI) is a well-established and commonly employed diffusion MRI technique in clinical and research on neuroimaging studies, which is based on a Gaussian model of diffusion processes [33]. In general, AD is associated with widespread reduced fractional anisotropy (FA) and increased mean diffusivity (MD) in several regions, most prominently in the frontal and temporal lobes, and along the cingulum, corpus callosum, uncinate fasciculus, superior longitudinal fasciculus, and MTL-associated tracts than healthy controls [34-37]. AcostaCabronero et al. reported increased axial diffusivity and MD in the splenium, which were the earliest abnormalities in $\mathrm{AD}$ [38]. FA and radial diffusivity (DR) differences in the corpus callosum, cingulum, and fornix were found to separate individuals with MCI who converted to AD from non-converters [39]. DTI was also found to be a better predictor of AD-specific MTL atrophy when compared to CSF biomarkers [40]. These findings suggested the potential clinical utility of DTI as early biomarkers of AD and its progression. However, an increase in MD and DR and a decrease in FA with advancing age in selective brain regions have been previously reported [41, 42]. Diffusion
MRI can be also used in the classifying of various stages of AD. Multimodal classification method, which combined fMRI and DTI, separated more MCI from healthy controls than single approaches [43].

In recent years, tau has emerged as a potential target for therapeutic intervention. Tau plays a critical role in the neurodegenerative process forming neurofibrillary tangles, which is a major hallmark of AD and correlates with clinical disease progression. Wells et al. applied multiparametric MRI, containing high-resolution structure MRI (sMRI), a novel chemical exchange saturation transfer (CEST) MRI, DTI, and ASL, and glucose CEST to measure changes of tau pathology in AD transgenic mouse [44].

Besides DWI MRI, perfusion-weighted imaging (PWI) is another advanced MR technique, which could measure the cerebral hemodynamics at the capillary level. Zimny et al. evaluated the correlation of MTL with both DWI and PWI in AD and MCI patients [45].

\section{Positron emission tomography}

PET is a specific imaging technique applying in researches of brain function and neurochemistry of small animals, medium-sized animals, and human subjects [46-48]. As a particular brain imaging technique, PET imaging has become the subject of intense research for the diagnosis and facilitation of drug development of $\mathrm{AD}$ in both animal models and human trials due to its non-invasive and translational characteristic. PET with various radiotracers is considered as a standard non-invasive quantitative imaging technique to measure $\mathrm{CBF}$, glucose metabolism, and $\beta$-amyloid and tau deposition.

\subsection{FDG-PET}

To date, 18F-FDG is one of the best and widely used neuroimaging tracers of PET, which employed for research and clinical assessment of AD [49]. Typical lower FDG metabolism was shown in the precuneus, posterior cingulate, and temporal and parietal cortex with progression to whole brain reductions with increasing disease progress in AD brains [50, 51]. FDG-PET imaging reflects the cerebral glucose metabolism, neuronal injury, which provides indirect evidence on cognitive function and progression that cannot be provided by amyloid PET imaging.

Schraml et al. [52] identified a significant association between hypometabolic convergence index and phenotypes using ADNI data. Some researchers also used 18F-FDGPET to analyze genetic information with multiple biomarkers to classify AD status, predicting cognitive decline or MCI to AD conversion [53-55]. Trzepacz et al. 
[56] reported multimodal $\mathrm{AD}$ neuroimaging study, using MRI, 11C-PiB PET, and 18F-FDG-PET imaging to predict MCI conversion to AD along with APOE genotype. Zhang et al. [57] compared the genetic modality single-nucleotide polymorphism (SNP) with sMRI, 18F-FDG-PET, and CSF biomarkers, which were used to differentiate healthy control, MCI, and AD. They found FDG-PET is the best modality in terms of accuracy.

\subsection{Amyloid beta PET}

$\mathrm{A} \beta$, the primary constituent of senile plaques, and tau tangles are hypothesized to play a primary role in the pathogenesis of $\mathrm{AD}$, but it is still hard to identify the fundamental mechanisms [58-60]. A $\beta$ plaque in brain is one of the pathological hallmarks of AD [61, 62]. Accumulation of $A \beta$ peptide in the cerebral cortex is considered one cause of dementia in AD [63]. Numerous studies have involved in vivo PET imaging assessing cortical $\beta$-amyloid burden [64-66].

A $\beta$ imaging using PET has been recognized as one of the most important methods for the early diagnosis of AD [67]. Numerous candidate compounds have been tested for A $\beta$ imaging, such as 11C-PiB [68], 18F-FDDNP [69], 11CSB-13 [70], 18F-BAY94-9172 [71], 18F-AV-45 [72], 18Fflutemetamol [73, 74], 11C-AZD2184 [75], and 18FADZ4694 [76], 11C-BF227 and 18F-FACT [77].

Several amyloid PET studies examined genotypes, phenotypes, or gene-gene interactions. Ramanan et al. [78] reported the GWAS results with $18 \mathrm{~F}-\mathrm{AV}-45$ reflecting the cerebral amyloid metabolism in AD for the first time. Swaminathan et al. [79] revealed the association between plasma $A \beta$ from peripheral blood and cortical amyloid deposition on 11C-PiB. Hohman et al. [80] reported the relationship between SNPs involved in amyloid and tau pathophysiology with 18F-AV-45 PET.

Among the PET tracers, 11C-PiB, which has a high affinity for fibrillar $A \beta$, is a reliable biomarker of underlying AD pathology $[68,81]$. It shows cortical uptake well paralleled with AD pathology [82, 83], has recently been approved for use by the Food and Drug Administration (FDA, April 2012) and the European Medicines Agency (January 2013). 18F-GE-067 (flutemetamol) and 18FBAY94-9172 (florbetaben) have also been approved by the US FDA in the last 2 years [84, 85].

18F-Florbetapir (also known as 18F-AV-45) exhibits high affinity specific binding to amyloid plaques. $18 \mathrm{~F}-\mathrm{AV}$ 45 labels $\mathrm{A} \beta$ plaques in sections from patients with pathologically confirmed AD [72].

It was reported in several research groups that $18 \mathrm{~F}-\mathrm{AV}-45$ PET imaging showed a reliability of both qualitative and quantitative assessments in AD patients, and $\mathrm{A} \beta+$ increased with diagnostic category (healthy control $<\mathrm{MCI}<\mathrm{AD}$ )
[82, 86, 87]. Johnson et al. used 18F-AV-45 PET imaging to evaluate the amyloid deposition in both MCI and AD patients qualitatively and quantitatively, and found that amyloid burden increased with diagnostic category (MCI < AD), age, and APOEE4 carrier status [88]. Payoux et al. reported the equivocal amyloid PET scans using $18 \mathrm{~F}$ AV-45 associated with a specific pattern of clinical signs in a large population of non-demented older adults more than 70 years old [89].

More and more researchers consider combination and comparison of multiple PET tracers targeting amyloid plaque imaging together. Bruck et al. compared the prognostic ability of 11C-PiB PET, 18F-FDG-PET, and quantitative hippocampal volumes measured with MR imaging in predicting MCI to AD conversion. They found that the FDG-PET and 11C-PiB PET imaging are better in predicting MCI to AD conversion [90]. Hatashita et al. used $11 \mathrm{C}-\mathrm{PiB}$ and FDG-PET imaging to identify MCI due to AD, 11C-PiB showed a higher sensitivity of $96.6 \%$, and FDG-PET added diagnostic value in predicting AD over a short period [91].

Besides, new A $\beta$ imaging agents were radiosynthesized. Yousefi et al. radiosynthesized a new $A \beta$ imaging agent $18 \mathrm{~F}-\mathrm{FIBT}$, and compared the three different $\mathrm{A} \beta$-targeted radiopharmaceuticals for PET imaging, including $18 \mathrm{~F}$ FIBT, 18F-florbetaben, and 11C-PiB [92]. 11C-AZD2184 is another new PET tracer developed for amyloid senile plaque imaging, and the kinetic behavior of 11C-AZD2184 is suitable for quantitative analysis and can be used in clinical examination without input function [75, 93, 94].

\section{Multimodality imaging: PET/MRI}

Several diagnostic techniques, including MRI and PET, are employed for the diagnosis and monitoring of AD [95]. Multimodal imaging could provide more information in the formation and key molecular event of $\mathrm{AD}$ than single method. It drives the progression of neuroimaging research due to the recognition of the clinical benefits of multimodal data [96], and the better access to hybrid devices, such as PET/MRI [97].

Maier et al. evaluated the dynamics of 11C-PiB PET, 15O- $\mathrm{H}_{2} \mathrm{O}-\mathrm{PET}$, and ASL-MRI in transgenic AD mice and concluded that the AD-related decline of $\mathrm{rCBF}$ was caused by the cerebral $A \beta$ angiopathy [98]. Edison et al. systematically compared $11 \mathrm{C}-\mathrm{PiB}$ PET and MRI in AD, MCI patients, and controls. They thought that $11 \mathrm{C}-\mathrm{PiB}$ PET was adequate for clinical diagnostic purpose, while MRI remained more appropriate for clinical research [99]. Zhou et al. investigated the interactions between multimodal PET/MRI in elder patients with MCI, AD, and healthy controls, and confirmed the invaluable application of 
amyloid PET and MRI in early diagnosis of AD [100]. Kim et al. reported that $A \beta$-weighted cortical thickness, which incorporates data from both MRI and amyloid PET imaging, is a consistent and objective imaging biomarker in $\mathrm{AD}$ [101].

\section{Other imaging modalities}

Multiphoton non-linear optical microscope imaging systems using ultrafast lasers have powerful advantages such as labelfree detection, deep penetration of thick samples, high sensitivity, subcellular spatial resolution, 3D optical sectioning, chemical specificity, and minimum sample destruction [102, 103]. Coherent anti-Stokes-Raman scattering (CARS), twophoton excited fluorescence (TPEF), and second-harmonic generation (SHG) microscopy are the most widely used biomedical imaging techniques [104-106].

Some researchers have reported in vivo imaging of senile plaque and collagen using multiphoton laser scanning microscopy or auto-fluorescence and SHG images in AD mouse model [107, 108]. Lee et al. developed a multimodal multiphoton non-linear optical microspectroscopy imaging system based on a small-diameter probe with gradient-index lenses combing CARS, TPEF, and SHG into one platform for imaging distinct molecular structures and components of brain tissue associated with AD transformation [109].

Metal dyshomeostasis is frequently observed in $\mathrm{AD}$ due to anomalous binding of metals such as iron $(\mathrm{Fe})$, copper $(\mathrm{Cu})$, and zinc $(\mathrm{Zn})$, or impaired regulation of redox-active metals inducing the neuronal damage. Neuroimaging of metals in a variety of intact brain cells and tissues is emerging as an important tool for increasing our understanding of the role of metal dysregulation in AD. Braidy et al. reviewed the metal bioimaging in AD [110]. Several imaging techniques, such as laser ablation inductively coupled mass spectrometry (MS), X-ray fluorescence microscopy, MALDI imaging mass spectrometry (MALDIMS), and Fourier transform infrared spectroscopy, have been used to study in AD [111-114]. Several limitations of metal bioimaging, such as lower spatial resolution and detection sensitivity, make it not as valuable as PET and MRI imaging.

\section{Perspective of neuroimaging in precision imaging}

Precision medicine is a phrase that is often used to describe how genetic information about a person's disease is being used to diagnose or treat their disease. Understanding the genetic changes that are in $\mathrm{AD}$ formation is leading to more effective treatment strategies. The prospect of a personalized or precision medicine for $\mathrm{AD}$, and for its incorporation in therapeutic trial design, is predicated on the ability to use an individual's genetic profile to refine predisposition to disease, characteristics such as likely rate of progression, and predicted therapeutic and side effect responses to various therapeutic strategies [115]. At present, the genetic data associated with $\mathrm{AD}$ clinical drug development were mainly focused on APOE, which was commonly used as stratification factor or covariate to adjust for heterogeneity $[116,117]$.

Ultimately, imaging-genetic endophenotype studies may provide a link between genetics and disease topography by elucidating those areas of the brain most associated with known and potential pathological genotypes. APOE genotype may be one important factor contributing to heterogeneity in sporadic $\mathrm{AD}$, as non- $\varepsilon 4$ status among EOAD patients correlates with atypicality [118].

\section{Conclusion}

This review provides a preliminary summary of the various neuroimaging techniques that have been explored for in vivo imaging of $\mathrm{AD}$. MRI and PET imaging are still the mainly used technique in the detection, assessment of AD. From a scientific perspective, more and more multimodality and multiparametric neuroimaging techniques should improve our understanding of brain function and open new insights into the pathophysiology of $\mathrm{AD}$. We expect exciting results will emerge from new neuroimaging applications that will provide scientific and medical benefits.

Acknowledgments The present study was supported by Grants from The Natural Science Foundation of Ningxia (No. NZ14131).

Funding This study was funded by the Natural Science Foundation of Ningxia (Grant No. NZ14131).

\section{Compliance with ethical standards}

Conflict of interest The authors confirm that this article has no conflicts of interest.

Open Access This article is distributed under the terms of the Creative Commons Attribution 4.0 International License (http://crea tivecommons.org/licenses/by/4.0/), which permits unrestricted use, distribution, and reproduction in any medium, provided you give appropriate credit to the original author(s) and the source, provide a link to the Creative Commons license, and indicate if changes were made.

\section{References}

1. Alzheimer's Association (2015) 2015 Alzheimer's disease facts and figures. Alzheimer's Dement 11(3):332-384 
2. Jack CR Jr, Knopman DS, Jagust WJ, Shaw LM, Aisen PS, Weiner MW et al (2010) Hypothetical model of dynamic biomarkers of the Alzheimer's pathological cascade. Lancet Neurol 9(1):119-128

3. Brodaty H, Breteler MM, Dekosky ST, Dorenlot P, Fratiglioni L, Hock C et al (2011) The world of dementia beyond 2020. J Am Geriatr Soc 59(5):923-927

4. Jack CR Jr, Knopman DS, Jagust WJ, Petersen RC, Weiner MW, Aisen PS et al (2013) Tracking pathophysiological progresses in Alzheimer's Disease: an updated hypothetical model of dynamic biomarkers. Lancet Neurol 12:207-216

5. Jack CR Jr, Wiste HJ, Vemuri P, Weigand SD, Senjem ML, Zeng $\mathrm{G}$ et al (2010) Brain beta-amyloid measures and magnetic resonance imaging atrophy both predict time-to-progression from mild cognitive impairment to Alzheimer's disease. Brain 133:3336-3348

6. Weiner MW, Veitch DP, Aisen PS, Beckett LA, Cairns NJ, Green RC et al (2013) The Alzheimer's Disease Neuroimaging Initiative: a review of papers published since its inception. Alzheimer's Dement 9(5):e111-e194

7. Liu S, Cai W, Liu S, Zhang F, Fulham M, Feng D et al (2015) Multimodal neuroimaging computing: a review of applications in neuropsychiatric disorders. Brain Inform 2:167-180

8. Lerch JP, Pruessner JC, Zijdenbos A, Hampel H, Teipel SJ, Evans AC (2005) Focal decline of cortical thickness in Alzheimer's disease identified by computational neuroanatomy. Cereb Cortex 15(7):995-1001

9. Frisoni GB, Fox NC, Jack CR Jr, Scheltens P, Thompson PM (2010) The clinical use of structural MRI in Alzheimer disease. Nat Rev Neurol 6(2):67-77

10. Hampel H, Frank R, Broich K, Teipel SJ, Katz RG, Hardy J et al (2010) Biomarkers for Alzheimer's disease: academic, industry and regulatory perspectives. Nat Rev Drug Discov 9(7):560-574

11. Stern Y (2009) Cognitive reserve. Neuropsychologia 47:2015-2028

12. Stern Y (2012) Cognitive reserve in ageing and Alzheimer's disease. Lancet Neurol 11(11):1006-1012

13. van den Heuvel MP, Hulshoff Pol HE (2010) Exploring the brain network: a review on resting-state fMRI functional connectivity. Eur Neuropsychopharmacol 20(8):519-534

14. Bozzali M, Dowling C, Serra L, Spanò B, Torso M, Marra C et al (2015) The impact of cognitive reserve on brain functional connectivity in Alzheimer's disease. J Alzheimer's Dis 44(1):243-250

15. Johnson NA, Jahng GH, Weiner MW, Miller BL, Chui HC, Jagust WJ et al (2005) Pattern of cerebral hypoperfusion in Alzheimer disease and mild cognitive impairment measured with arterial spin-labeling MR imaging: initial experience. Radiology 234(3):851-859

16. Kim SM, Kim MJ, Rhee HY, Ryu CW, Kim EJ, Petersen ET et al (2013) Regional cerebral perfusion in patients with Alzheimer's disease and mild cognitive impairment: effect of APOE Epsilon4 allele. Neuroradiology 55(1):25-34

17. Mak HK, Chan Q, Zhang Z, Petersen ET, Qiu D, Zhang L et al (2012) Quantitative assessment of cerebral hemodynamic parameters by QUASAR arterial spin labeling in Alzheimer's disease and cognitively normal elderly adults at 3-tesla. J Alzheimer's Dis 31(1):33-44

18. Petersen RC, Roberts RO, Knopman DS, Boeve BF, Geda YE, Ivnik RJ et al (2009) Mild cognitive impairment: ten years later. Arch Neurol 66:1447-1455

19. Dubois B, Feldman HH, Jacova C, Cummings JL, Dekosky ST, Bar-berger-Gateau $P$ et al (2010) Revising the definition of Alzheimer's disease: a new lexicon. Lancet Neurol 9:1118-1127

20. Binnewijzend MA, Kuijer JP, Benedictus MR, van der Flier WM, Wink AM, Wattjes MP et al (2013) Cerebral blood flow measured with 3D pseudocontinuous arterial spin-labeling MR imaging in Alzheimer disease and mild cognitive impairment: a marker for disease severity. Radiology 267(1):221-230

21. Binnewijzend MA, Kuijer JP, van der Flier WM, Benedictus MR, Möller CM, Pijnenburg YA et al (2014) Distinct perfusion patterns in Alzheimer's disease, frontotemporal dementia and dementia with Lewy bodies. Eur Radiol 24(2):2326-2333

22. Chen X, Huddleston DE, Langley J, Ahn S, Barnum CJ, Factor SA et al (2014) Simultaneous imaging of locus coeruleus and substantia nigra with a quantitative neuromelanin MRI approach. Magn Reson Imaging 32(10):1301-1306

23. Götz J, Ittner LM (2008) Animal models of Alzheimer's disease and frontotemporal dementia. Nat Rev Neurosci 9(7):532-544

24. Braakman N, Matysik J, Van Duinen SG, Verbeek F, Schliebs R, De Groot HJM et al (2006) Longitudinal assessment of Alzheimer's beta-amyloid plaque development in transgenic mice monitored by in vivo magnetic resonance microimaging. J Magn Reson Imaging 24:530-536

25. Langkammer C, Krebs N, Goessler W, Scheurer E, Ebner F, Yen K et al (2010) Quantitative MRI of brain iron: a postmortem validation study. Radiology 257:455-462

26. Langkammer C, Schweser F, Krebs N, Deistung A, Goessler W, Scheurer E et al (2012) Quantitative susceptibility mapping (QSM) as a means to measure brain iron? A post mortem validation study. Neuroimage 62:1593-1599

27. Spencer NG, Bridges LR, Elderfield K, Amir K, Austen B, Howe FA (2013) Quantitative evaluation of MRI and histological characteristics of the 5xFAD Alzheimer mouse brain. Neuroimage 76:108-115

28. Chamberlain R, Reyes D, Curran GL, Marjanska M, Wengenack TM, Poduslo JF et al (2009) Comparison of amyloid plaque contrast generated by $\mathrm{T} 2$-weighted, $\mathrm{T} 2 *$-weighted, and susceptibility-weighted imaging methods in transgenic mouse models of Alzheimer's disease. Magn Reson Med 61:1158-1164

29. Jack CR, Wengenack TM, Reyes DA, Garwood M, Curran GL, Borowsk BJ et al (2005) In vivo magnetic resonance microimaging of individual amyloid plaques in Alzheimer's transgenic mice. J Neurosci 25:10041-10048

30. Benveniste H, Ma Y, Dhawan J, Gifford A, Smith SD, Feinstein I et al (2007) Anatomical and functional phenotyping of mice models of Alzheimer's disease by MR microscopy. Ann NY Acad Sci 1097:12-29

31. Sillerud LO, Solberg NO, Chamberlain R, Heidrich JE, Brown DC, Brady CI et al (2013) SPION-enhanced magnetic resonance imaging of Alzheimer's plaques in A $\beta P P / P S-1$ transgenic mouse brain. J Alzheimer's Dis 34:349-365

32. Solberg NO, Chamberlain R, Vigil JR, Deck LM, Heidrich JE, Brown DC et al (2014) Optical and SPION-enhanced MR imaging shows that trans-stilbene inhibitors of NF- $\kappa \mathrm{B}$ concomitantly lower Alzheimer's disease plaque formation and microglial activation in A $\beta$ PP/PS-1 transgenic mouse brain. J Alzheimer's Dis 40(1):191-212

33. Basser PJ, Jones DK (2002) Diffusion-tensor MRI: theory, experimental design and data analysis - a technical review. NMR Biomed 15(7-8):456-467

34. Teipel SJ, Grothe M, Lista S, Toschi N, Garaci FG, Hampel H (2013) Relevance of magnetic resonance imaging for early detection and diagnosis of Alzheimer disease. Med Clin N Am 97(3):399-424

35. Sabbagh JJ, Kinney JW, Cummings JL (2013) Alzheimer's disease biomarkers: correspondence between human studies and animal models. Neurobiol Dis 56:116-130

36. Teipel SJ, Wegrzyn M, Meindl T, Frisoni G, Bokde AL, Fellgiebel A et al (2012) Anatomical MRI and DTI in the diagnosis of Alzheimer's disease: a European multicenter study. J Alzheimer's Dis 31(Suppl 3):S33-S47 
37. Lista S, Garaci FG, Toschi N, Hampel H (2013) Imaging epigenetics in Alzheimer's disease. Curr Pharm Des 19(36):6393-6415

38. Acosta-Cabronero J, Alley S, Williams GB, Pengas G, Nestor PJ (2012) Diffusion tensor metrics as biomarkers in Alzheimer's disease. PLoS One 7(11):e49072

39. van Bruggen T, Stieltjes B, Thomann PA, Parzer P, Meinzer HP, Fritzsche KH (2012) Do Alzheimer-specific microstructural changes in mild cognitive impairment predict conversion? Psychiatry Res 203(2-3):184-193

40. Selnes P, Aarsland D, Bjornerud A, Gjerstad L, Wallin A, Hessen E et al (2013) Diffusion tensor imaging surpasses cerebrospinal fluid as predictor of cognitive decline and medial temporal lobe atrophy in subjective cognitive impairment and mild cognitive impairment. J Alzheimer's Dis 33(3):723-736

41. Pfefferbaum A, Adalsteinsson E, Sullivan EV (2005) Frontal circuitry degradation marks healthy adult aging: evidence from diffusion tensor imaging. Neuroimage 26(3):891-899

42. Sullivan EV, Pfefferbaum A (2006) Diffusion tensor imaging and aging. Neurosci Biobehav Rev 30(6):749-761

43. Wee CY, Yap PT, Zhang D, Denny K, Browndyke JN, Potter GG et al (2012) Identification of MCI individuals using structural and functional connectivity networks. Neuroimage 59(3):2045-2056

44. Wells JA, O'Callaghan JM, Holmes HE, Powell NM, Johnson RA, Siow B et al (2015) In vivo imaging of tau pathology using multi-parametric quantitative MRI. Neuroimage 111:369-378

45. Zimny A, Bladowska J, Neska M, Petryszyn K, Guziński M, Szewczyk P et al (2013) Quantitative MR evaluation of atrophy, as well as perfusion and diffusion alterations within hippocampi in patients with Alzheimer's disease and mild cognitive impairment. Med Sci Monit 19:86-94

46. Lancelot S, Zimmer L (2010) Small-animal positron emission tomography as a tool for neuropharmacology. Trends Pharmacol Sci 31(19):411-417

47. Aznavour N, Cendres-Bozzi C, Lemoine L, Buda C, Sastre JP, Mincheva $Z$ et al (2012) MPTP animal model of Parkinsonism: dopamine cell death or only tyrosine hydroxylase impairment?A study using PET imaging, autoradiography and immunohistochemistry in the cat. CNS Neurosci Ther 18(11):934-941

48. Zimmer L, Luxen A (2012) PET radiotracers for molecular imaging in the brain: past, present and future. Neuroimage 61(2):363-370

49. Johnson KA, Fox NC, Sperling RA, Klunk WE (2012) Brain imaging in Alzheimer disease. Cold Spring Harb Perspect Med 2(4): $\mathrm{a} 006213$

50. Herholz K, Ebmeier K (2011) Clinical amyloid imaging in Alzheimer's disease. Lancet Neurol 10(7):667-670

51. Mosconi L (2005) Brain glucose metabolism in the early and specific diagnosis of Alzheimer's disease. FDG-PET studies in MCI and AD. Eur J Nucl Med Mol Imaging 32(4):486-510

52. Schraml F, Chen K, Ayutyanont N, Auttawut R, Langbaum JB, Lee W et al (2013) Association between an Alzheimer's diseaserelated index and gene dose. PLoS One 8(6):e67163

53. Gray KR, Aljabar P, Heckemann RA, Hammers A, Rueckert D (2013) Alzheimer's Disease Neuroimaging Initiative. Random forest-based similarity measures for multi-modal classification of Alzheimer's disease. Neuroimage 65:167-175

54. Shaffer JL, Petrella JR, Sheldon FC, Choudhury KR, Calhoun VD, Edward Coleman R et al (2013) Predicting cognitive decline in subjects at risk for Alzheimer disease by using combined cerebrospinal fluid, MR imaging, and PET biomarkers. Radiology 266(2):583-591

55. Gomar JJ, Conejero-Goldberg C, Davies P, Goldberg TE, Alzheimer's Disease Neuroimaging Initiative (2014) Extension and refinement of the predictive value of different classes of markers in ADNI: four-year follow-up data. Alzheimer's Dement 10:704-712
56. Trzepacz PT, Yu P, Sun J, Schuh K, Case M, Witte MM et al (2014) Comparison of neuroimaging modalities for the prediction of conversion from mild cognitive impairment to Alzheimer's dementia. Neurobiol Aging 35:143-151

57. Zhang Z, Huang H, Shen D (2014) Alzheimer's Disease Neuroimaging Initiative. Integrative analysis of multi-dimensional imaging genomics data for Alzheimer's disease prediction. Front Aging Neurosci 6:260

58. Benilova I, Karran E, De Strooper B (2012) The toxic A $\beta$ oligomer and Alzheimer's disease: an emperor in need of clothes. Nat Neurosci 15(3):349-357

59. Walsh DM, Klyubin I, Fadeeva JV, Cullen WK, Anwyl R, Wolfe MS et al (2002) Naturally secreted oligomers of amyloid beta protein potently inhibit hippocampal long-term potentiation in vivo. Nature 416(6880):535-539

60. Roberson ED, Scearce-Levie K, Palop JJ, Yan F, Cheng IH, Wu $\mathrm{T}$ et al (2007) Reducing endogenous tau ameliorates amyloid beta-induced deficits in an Alzheimer's disease mouse model. Science 316(5825):750-754

61. Dubois B, Feldman HH, Jacova C, Hampel H, Molinuevo JL, Blennow K et al (2014) Advancing research diagnostic criteria for Alzheimer's disease: the IWG-2 criteria. Lancet Neurol 13(6):614-629

62. Jack CR Jr, Albert MS, Knopman DS, McKhann GM, Sperling RA, Carrillo MC et al (2011) Introduction to the recommendations from the National Institute on Aging-Alzheimer's Association Workgroups on Diagnostic Guidelines for Alzheimer's Disease. Alzheimer's Dement 7(3):257-262

63. Hardy J, Selkoe DJ (2002) The amyloid hypothesis of Alzheimer's disease: progress and problems on the road to therapeutics. Science 297(5580):353-356

64. Tolboom N, Yaqub M, van der Flier WM, Boellaard R, Luurtsema G, Windhorst AD et al (2009) Detection of Alzheimer pathology in vivo using both ${ }^{11} \mathrm{C}$-PIB and ${ }^{18} \mathrm{~F}$-FDDNP PET. J Nucl Med 50(2):191-197

65. Kemppainen NM, Aalto S, Wilson IA, Nagren K, Helin S, Bruck A et al (2007) PET amyloid ligand $\left[{ }^{11} \mathrm{C}\right] \mathrm{PIB}$ uptake is increased in mild cognitive impairment. Neurology 68(19):1603-1606

66. Wolk DA, Zhang Z, Boudhar S, Clark CM, Pontecorvo MJ, Arnold SE (2012) Amyloid imaging in Alzheimer's disease: comparison of florbetapir and Pittsburgh compound-B positron emission tomography. J Neurol Neurosurg Psychiatry 83(9):923-926

67. Nordberg A (2004) PET imaging of amyloid in Alzheimer's disease. Lancet Neurol 3(9):519-527

68. Mathis CA, Wang Y, Holt DP, Huang GF, Debnath ML, Klunk WE (2003) Synthesis and evaluation of ${ }^{11} \mathrm{C}$-labeled 6-substituted 2-arylbenzothiazoles as amyloid imaging agents. J Med Chem 46(13):2740-2754

69. Agdeppa ED, Kepe V, Liu J, Flores-Torres S, Satyamurthy N, Petric A et al (2001) Binding characteristics of radiofluorinated 6-dialkylamino-2-naphthylethylidene derivatives as positron emission tomography imaging probes for beta-amyloid plaques in Alzheimer's disease. J Neurosci 21(24):RC189

70. Ono M, Wilson A, Nobrega J, Westaway D, Verhoeff P, Zhuang $\mathrm{ZP}$ et al (2003) ${ }^{11} \mathrm{C}$-labeled stilbene derivatives as Abeta-aggregate-specific PET imaging agents for Alzheimer's disease. Nucl Med Biol 30(6):565-571

71. Rowe CC, Ackerman U, Browne W, Mulligan R, Pike KL, O'Keefe G et al (2008) Imaging of amyloid beta in Alzheimer's disease with 18F-BAY94-9172, a novel PET tracer: proof of mechanism. Lancet Neurol 7(2):129-135

72. Choi SR, Golding G, Zhuang Z, Zhang W, Lim N, Hefti F et al (2009) Preclinical properties of ${ }^{18} \mathrm{~F}-\mathrm{AV}-45$ : a PET agent for Abeta plaques in the brain. J Nucl Med 50(11):1887-1894

73. Vandenberghe R, Van Laere K, Ivanoiu A, Salmon E, Bastin C, Triau E et al (2010) ${ }^{18} \mathrm{~F}$-flutemetamol amyloid imaging in 
Alzheimer disease and mild cognitive impairment: a phase 2 trial. Ann Neurol 68(3):319-329

74. Nelissen N, Van Laere K, Thurfjell L, Owenius R, Vandenbulcke M, Koole M et al (2009) Phase 1 study of the Pittsburgh compound $\mathrm{B}$ derivative ${ }^{18} \mathrm{~F}$-flutemetamol in healthy volunteers and patients with probable Alzheimer disease. J Nucl Med 50(8):1251-1259

75. Nyberg S, Jönhagen ME, Cselényi Z, Halldin C, Julin P, Olsson $\mathrm{H}$ et al (2009) Detection of amyloid in Alzheimer's disease with positron emission tomography using $\left[{ }^{11} \mathrm{C}\right] \mathrm{AZD} 2184$. Eur J Nucl Med Mol Imaging 36(11):1859-1863

76. Cselényi Z, Jönhagen ME, Forsberg A, Halldin C, Julin P, Schou $\mathrm{M}$ et al (2012) Clinical validation of ${ }^{18} \mathrm{~F}$-AZD4694, an amyloidbeta-specific PET radioligand. J Nucl Med 53(3):415-424

77. Shidahara M, Watabe H, Tashiro M, Okamura N, Furumoto S et al (2015) Quantitative kinetic analysis of PET amyloid imaging agents $\left[{ }^{11} \mathrm{C}\right] \mathrm{BF} 227$ and $\left[{ }^{18} \mathrm{~F}\right] \mathrm{FACT}$ in human brain. Nucl Med Biol 42(9):734-744

78. Ramanan VK, Risacher SL, Nho K, Kim S, Swaminathan S, Shen L et al (2014) APOE and BCHE as modulators of cerebral amyloid deposition: a florbetapir PET genome-wide association study. Mol Psychiatry 19(3):351-357

79. Swaminathan S, Risacher SL, Yoder KK, West JD, Shen L, Kim $S$ et al (2014) Association of plasma and cortical amyloid beta is modulated by APOE epsilon4 status. Alzheimer's Dement 10(1):e9-e18

80. Hohman TJ, Koran ME, Thornton-Wells TA, Alzheimer's Neuroimaging Initiative (2014) Interactions between GSK3beta and amyloid genes explain variance in amyloid burden. Neurobiol Aging 35(3):460-465

81. Klunk WE, Engler H, Nordberg A, Wang Y, Blomqvist G, Holt $\mathrm{DP}$ et al (2004) Imaging brain amyloid in Alzheimer' disease with Pittsburgh compound-B. Ann Neurol 55(3):306-319

82. Clark CM, Schneider JA, Bedell BJ, Beach TG, Bilker WB, Mintun MA et al (2011) Use of florbetapir-PET for imaging beta-amyloid pathology. JAMA 305(3):275-283

83. Choi SR, Schneider JA, Bennett DA, Beach TG, Bedell BJ, Zehntner SP et al (2012) Correlation of amyloid PET ligand florbetapir F18 binding with Abeta aggregation and neuritic plaque deposition in postmortem brain tissue. Alzheimer Dis Assoc Disord 26(1):8-16

84. Koole M, Lewis DM, Buckley C, Nelissen N, Vandenbulcke M, Brooks DJ et al (2009) Whole-body biodistribution and radiation dosimetry of ${ }^{18} \mathrm{~F}-\mathrm{GE} 067$ : a radioligand for in vivo brain amyloid imaging. J Nucl Med 50(5):818-822

85. Barthel H, Gertz HJ, Dresel S, Peters O, Bartenstein P, Buerger $\mathrm{K}$ et al (2011) Cerebral amyloid-beta PET with florbetaben $\left({ }^{18} \mathrm{~F}\right)$ in patients with Alzheimer's disease and healthy controls: a multicentre phase 2 diagnostic study. Lancet Neurol 10(5):424-435

86. Fleisher AS, Chen K, Liu X, Roontiva A, Thiyyagura P, Ayutyanont $\mathrm{N}$ et al (2011) Using positron emission tomography and florbetapir F18 to image cortical amyloid in patients with mild cognitive impairment or dementia due to Alzheimer disease. Arch Neurol 68(11):1404-1411

87. Namiki C, Takita Y, Iwata A, Momose T, Senda M, Okubo Y et al (2015) Imaging characteristics and safety of florbetapir $\left({ }^{18} \mathrm{~F}\right)$ in Japanese healthy volunteers, patients with mild cognitive impairment and patients with Alzheimer's disease. Ann Nucl Med 29(7):570-581

88. Johnson KA, Sperling RA, Gidicsin C, Carmasin JS, Maye JE, Coleman RE et al (2013) Florbetapir (F18-AV-45) PET to assess amyloid burden in Alzheimer's disease dementia, mild cognitive impairment, and normal aging. Alzheimer's Dement 9(5 Suppl):S72-S83
89. Payoux P, Delrieu J, Gallini A, Adel D, Salabert AS, Hitzel A et al (2015) Cognitive and functional patterns of nondemented subjects with equivocal visual amyloid PET findings. Eur J Nucl Med Mol Imaging 42(9):1459-1468

90. Bruck A, Virta JR, Koivunen J, Koikkalainen J, Scheinin NM, Helenius $\mathrm{H}$ et al (2013) [11C]PIB, $\left[{ }^{18} \mathrm{~F}\right] \mathrm{FDG}$ and MR imaging in patients with mild cognitive impairment. Eur J Nucl Med Mol Imaging 40(10): 1567-1572

91. Hatashita S, Yamasaki H (2013) Diagnosed mild cognitive impairment due to Alzheimer's disease with PET biomarkers of beta amyloid and neuronal dysfunction. PLoS One 8(6):e66877

92. Yousefi BH, von Reutern B, Scherübl D, Manook A, Schwaiger M, Grimmer T et al (2015) FIBT versus florbetaben and PiB: a preclinical comparison study with amyloid-PET in transgenic mice. EJNMMI Res 5:20

93. Johnson AE, Jeppsson F, Sandell J, Wensbo D, Neelissen JA, Juréus A et al (2009) AZD2184: a radioligand for sensitive detection of beta-amyloid deposits. $\mathrm{J}$ Neurochem 108(5): 1177-1186

94. Ito H, Shimada H, Shinotoh H, Takano H, Sasaki T, Nogami T et al (2014) Quantitative analysis of amyloid deposition in Alzheimer disease using PET and the radiotracer 11CAZD2184. J Nucl Med 55(6):932-938

95. Catana C, Drzezga A, Heiss WD, Rosen BR (2012) PET/MRI for neurologic applications. J Nucl Med 53(12):1916-1925

96. Zhang D, Wang Y, Zhou L, Yuan H, Shen D (2011) Multimodal classification of Alzheimer's disease and mild cognitive impairment. Neuroimage 55:856-867

97. Bisdas S, Nagele T, Schlemmer P, Boss A, Claussen C, Pichler B et al (2010) Switching on the lights for real-time multimodality tumor neuroimaging: the integrated positron emission tomography/MR imaging system. Am J Neuroradiol 31:610-614

98. Maier FC, Wehrl HF, Schmid AM, Mannheim JG, Wiehr S, Lerdkrai $C$ et al (2014) Longitudinal PET-MRI reveals $\beta$ amyloid deposition and rCBF dynamics and connects vascular amyloidosis to quantitative loss of perfusion. Nat Med 20(12):1485-1492

99. Edison P, Carter SF, Rinne JO, Gelosa G, Herholz K, Nordberg A et al (2013) Comparison of MRI based and PET template based approaches in the quantitative analysis of amyloid imaging with PIB-PET. Neuroimage 70:423-433

100. Zhou Y, Yu F, Duong TQ, Alzheimer's Disease Neuroimaging Initiative (2015) White matter lesion load is associated with resting state functional MRI activity and amyloid PET but not FDG in mild cognitive impairment and early Alzheimer's disease patients. J Magn Reson Imaging 41(1):102-109

101. Kim CM, Hwang J, Lee JM, Roh JH, Lee JH, Koh JY et al (2015) Amyloid beta-weighted cortical thickness: a new imaging biomarker in Alzheimer's disease. Curr Alzheimer Res 12(6):563-571

102. Zipfel WR, Williams RM, Webb WW (2003) Nonlinear magic: multiphoton microscopy in the biosciences. Nat Biotechnol 21(11):1369-1377

103. Lim RS, Kratzer A, Barry NP, Miyazaki-Anzai S, Miyazaki M, Mantulin WW (2010) Multimodal CARS microscopy determination of the impact of diet on macrophage infiltration and lipid accumulation on plaque formation in ApoE-deficient mice. J Lipid Res 51(7): 1729-1737

104. Billecke N, Rago G, Bosma M, Eijkel G, Gemmink A, Leproux $P$ et al (2014) Chemical imaging of lipid droplets in muscle tissues using hyperspectral coherent Raman microscopy. Histochem Cell Biol 141(3):263-273

105. Lee YJ, Vega SL, Patel PJ, Aamer KA, Moghe PV, Cicerone MT (2014) Quantitative, label-free characterization of stem cell differentiation at the single-cell level by broadband coherent 
anti-Stokes Raman scattering microscopy. Tissue Eng C 20(7):562-569

106. Le TT, Yue S, Cheng JX (2010) Shedding new light on lipid biology with coherent anti-Stokes Raman scattering microscopy. J Lipid Res 51(11):3091-3102

107. Christie RH, Bacskai BJ, Zipfel WR, Williams RM, Kajdasz ST, Webb WW et al (2001) Growth arrest of individual senile plaques in a model of Alzheimer's disease observed by in vivo multiphoton microscopy. J Neurosci 21(3):858-864

108. Kwan AC, Duff K, Gouras GK, Webb WW (2009) Optical visualization of Alzheimer's pathology via multiphoton-excited intrinsic fluorescence and second harmonic generation. Opt Express 17(5):3679-3689

109. Lee JH, Kim DH, Song WK, Oh MK, Ko DK (2015) Label-free imaging and quantitative chemical analysis of Alzheimer's disease brain samples with multimodal multiphoton nonlinear optical microspectroscopy. J Biomed Opt 20(5):56013

110. Braidy N, Poljak A, Marjo C, Rutlidge H, Rich A, Jayasena T et al (2014) Metal and complementary molecular bioimaging in Alzheimer's disease. Front Aging Neurosci 6:138

111. Becker JS, Matusch A, Palm C, Salber D, Morton KA, Becker JS (2010) Bioimaging of metals in brain tissue by laser ablation inductively coupled plasma mass spectrometry (LA-ICP-MS) and metallomics. Metallomics 2(2):104-111

112. Leskovjan AC, Kretlow A, Lanzirotti A, Barrea R, Vogt S, Miller LM (2011) Increased brain iron coincides with early plaque formation in a mouse model of Alzheimer's disease. Neuroimage 55:32-38

113. Rohner TC, Staab D, Stoeckli M (2005) MALDI mass spectrometric imaging of biological tissue sections. Mech Ageing Dev 126:177-185

114. Komatsu H, Liu L, Murray IV, Axelsen PH (2007) A mechanistic link between oxidative stress and membrane mediated amyloidogenesis revealed by infrared spectroscopy. Biochim Biophys Acta 1768:1913-1922

115. Saykin AJ, Shen L, Yao X, Kim S, Nho K, Risacher SL et al (2015) Genetic studies of quantitative MCI and AD phenotypes in ADNI: progress, opportunities, and plans. Alzheimer's Dement 11:792-814

116. Doody RS, Thomas RG, Farlow M, Iwatsubo T, Vellas B, Joffe $S$ et al (2014) Phase 3 trials of solanezumab for mild-to-moderate Alzheimer's disease. N Engl J Med 370:311-321

117. Salloway S, Sperling R, Fox NC, Blennow K, Klunk W, Raskind $M$ et al (2014) Two phase 3 trials of bapineuzumab in mild-tomoderate Alzheimer's disease. N Engl J Med 370:322-333

118. Van der Flier WM, Pijnenburg YA, Fox NC, Scheltens P (2010) Early-onset versus late-onset Alzheimer's disease: the case of the missing APOE $\varepsilon 4$ allele. Lancet Neurol 10:280-288
Qian Zhao is working as an Associate Chief Physician in the Department of Nuclear Medicine at General Hospital of Ningxia Medical University. She obtained her Ph.D. in Radiology and Nuclear Medicine from Peking University in 2013; M.D. in Radiology and Nuclear Medicine from Ningxia Medical University in 2007; and Bachelor Degree in Clinical Medicine from Haerbin Medical University in 2004. Her areas of research interests include molecular imaging, molecular probes, translational medicine and nuclear medicine. Her current research is focused on early diagnosis of oncological and neurological diseases.

Xueqi Chen is a Doctoral Candidate in Nuclear Medicine in Peking University First Hospital, Beijing, China since September 2011, expecting the completion of Ph.D. in June 2016, under the mentorship of Dr. Rongfu Wang. From September 2014 to August 2015, she was a visiting Ph.D. Student in Johns Hopkins University School of Medicine, Baltimore, MD, USA under the JHU-PKU joint training program with Dr. Yun Zhou as her mentor. She completed her Bachelor of Clinical Medicine in Xi' an Jiaotong University, Xi' an, Shaanxi, China in 2011. Her areas of research interests include nuclear oncology, molecular imaging, molecular probes, translational medicine, quantitative analysis of multimodality imaging data in nuclear medicine and molecular imaging. Her current research is focused on multiparametric PET values in the prediction of Alzheimer's disease progress and non-invasive imaging of a novel integrin $\alpha_{v} \beta_{3}$-specific delivery carrier for improving transfection of siRNA in malignant tumors in vivo.

Yun Zhou is currently working as an Assistant Professor in the Division of Nuclear Medicine and Molecular Imaging, The Russell H. Morgan Department of Radiology and Radiological Science, Johns Hopkins University School of Medicine. He is also working as a Guest Professor at the Department of Nuclear Medicine, Peking University First Hospital. He obtained his Ph.D. in Biomedical Physics and M.S. in Biomathematics from the University of California, Los Angeles in 2000 and 1996, respectively; and his M.S. in Mathematics from the Beijing Normal University in 1988; and B.S. in Mathematics from Anhui Normal University in 1984. His areas of research interests include quantitative functional imaging with PET, SPECT, CT, MRI, and its applications in neurology, oncology, and CNS drug evaluation. His current research is focused on PET kinetic modeling and parametric imaging, quantitative amyloid- $\beta$ and tau imaging with PET in Alzheimer's disease patients, dopamine and serotonin transporter and receptor PET imaging in Parkinson's disease and depression, and drug evaluation for schizophrenia. 